\title{
The long-term psychiatric and medical prognosis of perinatal mental illness
}

\author{
Samantha Meltzer-Brody, MD, MPH ${ }^{a},{ }^{*}$ and Alison Stuebe, MD, MSc ${ }^{b}$ \\ aDepartment of Psychiatry, University of North Carolina at Chapel Hill, NC, USA \\ bDepartment of Obstetrics and Gynecology, University of North Carolina at Chapel Hill, NC, USA
}

\section{Abstract}

The perinatal period provides an important window into a woman's long-term health. Perinatal mental illness is a common condition conferring potential serious long-term psychiatric and medical consequences for the mother and family. It is known that childbirth acts as a powerful trigger for depressive episodes in some women, and that women with histories of a mood disorder are particularly vulnerable. Some evidence links perinatal mental illness with obstetrical complications and reduced lactation initiation and duration. Therefore, perinatal mental illness may be a marker for long-term risk, and may contribute directly to subsequent cardiometabolic disease through both neuroendocrine mechanisms and the effects of mental illness on health behaviours. In clinical practice, these associations underscore the importance of screening and treating women with perinatal mental illness to ensure best possible long-term outcomes. Early screening and treatment may both mitigate the primary disease process and reduce the risk of comorbid medical conditions.

\section{Keywords}

perinatal mental illness; perinatal depression; major depression; bipolar disorder; obsessivecompulsive disorder; obstetrical complications; lactation; gestational diabetes

\section{Introduction}

The perinatal period is a critical time in a women's life that is influenced by multiple factors that have consequences on the outcome of the pregnancy, but also may have significant long-term implications. Misri et al. [1] cogently described a 'women's life span approach model to perinatal health,' which recognises the myriad of determinants in the perinatal period and integrates the social, psychological, behavioural, environmental and biological forces that shape pregnancy and provide a model that demonstrates the interrelationships that influence long-term health. In this model, the entire life span is considered, including the role of preconception health factors that may occur long before pregnancy begins (i.e. pre-pregnancy obesity), as well as the multiple determinants that require targeted

\author{
(C) 2013 Elsevier Ltd. All rights reserved. \\ *Corresponding author. Tel.: +1 919445 0215., meltzerb@ med.unc.edu (S. Meltzer-Brody). \\ Conflict of interest \\ None declared.
}

Publisher's Disclaimer: This is a PDF file of an unedited manuscript that has been accepted for publication. As a service to our customers we are providing this early version of the manuscript. The manuscript will undergo copyediting, typesetting, and review of the resulting proof before it is published in its final citable form. Please note that during the production process errors may be discovered which could affect the content, and all legal disclaimers that apply to the journal pertain. 
intervention to allow for improvements in perinatal outcomes [1]. This is important, as growing evidence suggests that complications during the perinatal period may provide a window into a woman's long-term health [2]. The stressors of major hormonal fluctuations, sleep deprivation, and caring for a new infant may trigger perinatal mental illness and unmask a psychobiological vulnerability that may manifest as psychiatric disease in later life. In this chapter, we take a multiple determinants approach and discuss long-term psychiatric and medical consequences of perinatal mental illness. We first examine the longterm risk of developing a chronic mood disorder (both unipolar and bipolar depression) among women who experience perinatal mental health and also discuss perinatal obsessivecompulsive disorder and long-term prognosis. Second, we discuss the strength of the evidence linking perinatal mental illness with obstetrical and other medical outcomes, including weight retention, pregnancy complications, and lactation difficulties.

\section{Long-term psychiatric complications of perinatal mental illness}

Perinatal mental illness confers potential serious long-term psychiatric and medical consequences for the mother, her baby, and the family [3-5]. Some are the result of maladaptive behaviours by women who experience depression during pregnancy. Women with antenatal depression are less likely to participate in recommended prenatal care practices, and are at increased risk of engaging in risky health behaviours, such as smoking and substance use in pregnancy [4], thereby increasing risk of adverse obstetrical outcomes, including preterm birth and low birth weight [6-8], and long-term adverse health effects on the child. In addition, fetal exposure to maternal suicide attempts is associated with mental retardation and serious congenital abnormalities [9-11]. Research shows that a significant percentage of women who experience perinatal depression and anxiety will develop recurrent long-term mood disorders (unipolar and bipolar depression) [12,13]. Although onset of perinatal mood and anxiety symptoms may begin during pregnancy or the postpartum period, untreated antenatal depression has consistently been shown to be one of the greatest risk factors for postpartum depression (PPD) [14-16].

Postpartum depression is one of the greatest causes of maternal mortality and long-term morbidity $[17,18]$. Women with PPD are at increased risk of maternal suicide, infanticide, decreased maternal sensitivity, and attachment with the infant $[17,19,20]$. In addition to the far-reaching consequences on the infant, maternal depression also strongly affects paternal mood, and has important consequences on the short and long-term functioning of the family [21]. Therefore, perinatal mental illness often adversely affects the couple's relationship, leading to increased marital discord and less marital satisfaction [22].

\section{Biological underpinnings and long-term risk of perinatal mental illness}

Childbirth acts as a powerful trigger for depressive episodes in some women, and women with histories of mood disorders are vulnerable to a psychobiological postpartum trigger [23-25]. Recent work by Di Florio et al. [23] documents that more than $70 \%$ of parous women with a history of a mood disorder will experience at least one perinatal mood episode in relationship to pregnancy and childbirth. Moreover, women with previous histories of a mood disorder (unipolar and bipolar disorder) are likely to experience recurrent episodes, and are particularly vulnerable to the cessation of treatment during the vulnerable perinatal period [26-28].

\section{Unipolar major depression}

Most women with perinatal mental illness will experience unipolar major depressive disorder [29-31]. Moreover, the recurrence risk of PPD in women who have suffered one episode of major depression after childbirth is about 25\% [32], and can often become a 
chronic issue $[12,13,33]$. To establish evidence-based, long-term treatment recommendations and prognosis for women who have experienced perinatal depression is critically important so that recurrent illness can be prevented, but also challenging because the underlying pathophysiology is not fully understood [34].

Although many unanswered questions about the underlying pathophysiology of perinatal depression remain unanswered, previous research by Bloch et al. [35,36] has shown that currently euthymic women with previous histories of PPD experienced onset of depression and increased cortisol response when undergoing an experimental protocol consisting of high-dose gonadal steroid administration followed by abrupt withdrawal. This observed effect in women with a history of PPD (who experienced onset of depression) differed significantly to the group of women without a history of PPD who experienced no depressive symptoms when exposed to the same protocol. This work, therefore, supports the hypothesis of an underlying psychobiological vulnerability related to the onset of PPD or a consequence of an earlier depressive episode [35,36].

Evidence also suggests a genetic basis of perinatal depression, including studies of the familiality of PPD [24,37], examination of heritability [38], and genome-wide linkage [39]. To date, however, consistent and reliable detection of biomarkers in women at risk for PPD do not exist, and it has been difficult to identify consistently state biomarkers for major depression in general $[40,41]$.

Therefore, clinical history becomes exceedingly important when counselling women with histories of perinatal mental illness to discuss strategies for preventing disease recurrence. Research on preventing recurrent perinatal mental illness is limited [32], but efficacy of antidepressant therapy (ser-traline) in preventing recurrence of postpartum-onset major depression was demonstrated in a pilot study that showed sertraline performed better than placebo, and the length of time to recurrence was significantly greater in women treated with sertraline compared with women treated with placebo [42]. Psychological interventions to prevent perinatal depression have had conflicting results $[43,44]$, although recent work suggests psychological interventions are most likely to be effective when delivered to at-risk women with antenatal depression, in an attempt to prevent PPD.

Overall, women with a prior history of perinatal depression are at significantly increased risk for a recurrent episode in both the context of childbearing and outside of the perinatal period. Moreover, women with a history of MDD and PPD are often understandably concerned about recurrence after childbirth, necessitating preventive therapy [45]. Careful monitoring and longitudinal follow up with skilled mental-health providers is critical for best possible outcomes for mother, child, and family.

\section{Bipolar depression}

Bipolar disorder confers a unique and serious risk of perinatal mental illness. The biological link between childbirth and bipolar disorder has been well documented in family and genetic studies [46-48]. Large-scale epidemiologic population registry studies by Munk-Olsen et al. $[49,50]$ have documented that childbirth has a critically important influence on the onset and course of bipolar affective disorder. About $14 \%$ of women with a first-time psychiatric contact during the first month after delivery converted to bipolar affective disorder within the first 15 years after their initial postpartum episode, which was three times more often than women with initial psychiatric contact at other points [49]. Women with bipolar disorder are at increased risk of depression, mania, and psychosis in the perinatal period [51]. Episodes of postpartum psychosis, a life-threatening, but rare, psychiatric emergency, are generally, but not always, considered a presentation of bipolar affective disorder [52]. 
As women with bipolar disorder are at significant risk of relapse at the time of childbirth, medication prophylaxis should be strongly considered [53-55]. Discontinuation of medication during pregnancy significantly increases the risk of postpartum recurrence of perinatal mental illness [27,28]; therefore, women with bipolar disorder should be monitored closely during pregnancy and post-partum [53]. Treatment considerations for women with documented bipolar disorder and histories of postpartum psychosis should balance the risks and benefits to both the mother and fetus [56]. In particular, recent work by Bergink et al. [53] documented that women with a history of postpartum psychosis only, compared with those with histories of bipolar disorder, had significant differences in clinical outcomes and prophylaxis requirements; namely, that women with bipolar disorder were much more likely to relapse during pregnancy and have a less robust response to prophylactic treatment with a mood stabiliser [53]. Therefore, these findings have important prognostic implications for women with bipolar disorder, and suggest that perinatal mental illness needs to be taken seriously in women with more severe mood disorders, and that long-term follow up is critical, especially in women with bipolar disorder.

\section{Perinatal obsessive-compulsive symptoms and long-term risk of obsessive-compulsive disorder}

Ruminating and obsessional thoughts are commonly reported in women with perinatal mental illness, and often focus on well-being of the fetus [57]. In contrast to ruminating symptoms, obsessive-compulsive disorder (OCD) is characterised by persistent and unwanted obsessional thoughts and the implementation of compulsive rituals and behaviours aimed at neutralising or managing the intrusive thoughts (DSM-IV, 1994 \#573). Research documents an increased incidence of both obsessive-compulsive symptoms and a clinical diagnosis of OCD in postpartum women, although whether postpartum OCD is a distinct clinical entity remain controversial [58-61].

The underlying pathophysiology of perinatal OCD symptoms is not known, but reports have shown that changing levels of gonadal steroids (oestradiol and progesterone) at the time of delivery may alter the transmission of serotonin and dopamine [62]. Oxytocin has also been implicated in the onset of postpartum OCD [63,64]. Women suffering from postpartum OCD symptoms experience intense distress, and find the senseless and intrusive thoughts threatening, leading to obsessive preoccupation and urges to perform anxiety-reducing rituals [65].

Therefore, it is critical that clinicians screen for OCD symptoms in the perinatal period, independent from, or comorbid with, perinatal depression [60]. Serotonergic antidepressant medications have been shown to be efficacious in the treatment of OCD, along with exposure-based cognitive-behavioral therapy, and other evidence-based psychotherapeutic modalities $[60,66]$. Some women require the addition of an atypical antipsychotic to achieve remission of symptoms, and at least one study has documented the efficacy of this approach using quetiapine in the perinatal period [67]. Overall, depressive and anxiety symptoms are often associated with obsessive and neutralising compulsive symptoms in pregnancy and postpartum. Perinatal OCD symptoms require careful evaluation and targeted treatment to ensure remission. The long-term prognosis of OCD that begins in the postpartum period is unknown, and longitudinal studies are needed.

\section{Long-term obstetrical and medical outcomes of perinatal mental illness}

Research on maternal perinatal mental illness with non-psychiatric long-term outcomes is scant; however, evidence of a link between perinatal anxiety and depression has been found with both pregnancy complications and reduced lactation initiation and duration. Both pregnancy complications and impaired lactation are associated with long-term maternal 
disease risk, and so it is plausible that women who experience perinatal mental illness may be at increased risk of other chronic disease conditions. The causal nature of these associations is unclear, and it is likely that pregnancy complications, perinatal mental illness, and impaired lactation are manifestations of underlying psychobiological vulnerability that may also contribute to long-term disease risk (Fig. 1). In this context, perinatal mental illness may be a marker for long-term risk, or it may contribute directly to subsequent cardiometabolic disease through both neuroendocrine mechanisms such as dysregulated stress reactivity, and through the effects of mental illness on health behaviours.

Here, we discuss the strength of the evidence linking perinatal mood disorders with weight retention, pregnancy complications, and lactation difficulties, and consider the potential implications of these associations for treatment strategies and future research.

\section{Postpartum depression and gestational weight retention}

The burgeoning obesity epidemic has drawn attention to weight gain during pregnancy as a potential modifiable risk factor for metabolic disease in women [68]. Several authors have reported an association between perinatal depression and retained gestational weight gain. Herring et al. [69] measured the association between new-onset PPD, defined as an Edinburgh Postnatal Depression score (EPDS) greater than 12 at 6 months postpartum, with an EPDS of 12 or less during pregnancy, and retention of at least $5 \mathrm{~kg}$ at 1 year postpartum [69]. Among the 37 women with new-onset postpartum depression, 27\% (10 out of 37) retained $5 \mathrm{~kg}$ or more at 1 year, compared with 11\% (81 out of 736) of those with EPDS 12 or less during pregnancy and postpartum. This association persisted in multivariate models adjusting for pre-pregnancy body mass index (BMI), gestational weight gain, age, race and ethnicity, income, marital status, and education.

A subsequent study in the same population quantified the association between short maternal sleep duration, defined as $5 \mathrm{~h}$ or less a day, at 6 months postpartum, and maternal metabolic health at 3 years postpartum [70]. Compared with over $5 \mathrm{~h}$ per day of sleep, $5 \mathrm{~h}$ of sleep or less was associated with greater weight retention at 3 years $(1.5 \mathrm{~kg}, 95 \%$ CI 0.2 to 2.8), greater subscapular plus triceps skinfold thickness ( $3.95 \mathrm{~mm}, 95 \%$ CI 1.27 to 6.60 ), and greater waist circumference $(3.10 \mathrm{~cm}, 95 \%$ CI 1.25 to 4.94$)$. To the extent that poor sleep may be associated with postpartum depression, these results provide tentative evidence of a lasting association between mood disorders and maternal adiposity.

Pre-pregnancy body mass index (BMI) is another important factor that can determine the extent of weight gain during pregnancy, and may differ based on depression status. Bodnar et al. [71] found that depressed women during pregnancy had a higher pre-pregnancy BMI. Specifically, among women with weight gain during pregnancy within and above standard recommendations, pregravid overweight status was associated with a greater likelihood of major depression during pregnancy, thereby adding to an ongoing risk for obesity [71].

Bogaerts et al. [72] measured the association between early pregnancy anxiety, indexed by Spielberger Trait Anxiety Score at enrollment in the first trimester, and postpartum weight retention at 6 months among 150 obese women who participated in a lifestyle intervention during pregnancy [72]. They found that higher trait anxiety predicted greater weight retention at 6 months postpartum.

In the Danish National Birth Cohort, Pedersen et al. [73] measured the association between psychological wellbeing, indexed by questions from the Symptoms Checklist-92 and the General Health Questionnaire 60, and retained weight at 6 and 18 months postpartum [73]. Feeling depression or anxious during pregnancy was associated with greater weight retention at 6 months (mean $1.81 \mathrm{~kg}$; standard deviation $5.05 v$ mean $1.27 \mathrm{~kg}$; standard 
deviation 4.57; $P<0.01$ ) and at 18 months post-partum (mean $0.29 \mathrm{~kg}$; standard deviation $5.10 v$ mean $-0.06 \mathrm{~kg}$; standard deviation $4.67 ; P<0.01$ ). In models adjusting for parity, pre-pregnancy BMI, smoking, and exercise during pregnancy, this association persisted: feeling depressed or anxious was associated with a 1.35 -fold risk of $5 \mathrm{~kg}$ or more of retained weight at 6 months (95\% CI 1.27 to 1.44), and a 1.34-fold risk at 18 months (95\% CI 1.24 to 1.45).

These studies suggest that perinatal depression, anxiety, or both, may be independent risk factors for retained gestational weight gain. Such weight retention is associated with longterm metabolic disease risk [74,75], implicating perinatal depression as a potentially modifiable risk factor for long-term maternal metabolic disease. Moreover, new research suggests that postpartum lipids (total cholesterol, HDL-C, and LDL-C) are significantly elevated in the early postpartum period and do not return to less than $200 \mathrm{mg} / \mathrm{dL}$ until 6 weeks postpartum in women with PPD [76]. The magnitude and duration of the elevated lipids are consistent with the sparse published data on non-depressed women, and represents an important step in understanding the physiologic changes that may influence metabolic disease risk and affect long-term health outcomes in women with PPD [76].

\section{Perinatal mood disorders and pregnancy complications}

In observational studies, depression and anxiety during pregnancy have been associated with adverse pregnancy outcomes [8]. Grote et al. [8] conducted a large meta-analysis and found that women with antenatal depression were at increased risk for preterm birth and low birth weight, suggesting that antenatal depression needs identification and treatment. These results were replicated in a recent meta-analysis, by Grigoriadis et al., [77] who also found an increased odds of preterm birth among women with depression during pregnancy (OR $1.37,95 \%$ CI 1.04 to 1.81 ). Other investigators have reported associations between antenatal mood disorders and pre-eclampsia. Kurki et al. [78] measured maternal mood at 16 weeks using a shortened version of the Beck Depression Inventory and a single Likert-scale measure of anxiety. The presence of depression or anxiety symptoms in early pregnancy was associated with a 3.1-fold risk of pre-eclampsia (95\% CI 1.4 to 6.9). Qiu et al. [79] measured the association between maternal mood disorder, ascertained by self-report in early pregnancy or medical records review, and diagnosis of pre-eclampsia, in a prospective cohort study of 2601 women enrolled in early pregnancy. They found that a mood or anxiety disorder diagnosis was associated with an increased risk of preeclampsia (MV-adjusted OR $2.12,95 \%$ CI 1.02 to 4.45 ). Other studies have found no association between prenatal depression and pre-eclampsia $[80,81]$.

Diabetes during pregnancy has also been associated with mood symptoms. In a retrospective cohort study of Medicaid administrative claims, women with a diagnosis code or prescription for diabetes medication during pregnancy were more likely to have an ICD-9 depression diagnosis during pregnancy $(5.8 v 2.7 \%)$ and in the postpartum period $(13.1 v$ $7.3 \%$ ) [82]. Women with a diabetes diagnosis or medication were 1.69 times as likely (95\% CI 1.27 to 2.23) to have isolated postpartum depression, and 1.88 times as likely (95\% CI 1.47 to 2.41 ) to have postpartum depression with or without prenatal depression. Excessive gestational weight gain may further contribute to postpartum depression symptoms: in a recent prospective study of women with gestational diabetes, gestational weight gain was independently associated with depressive symptoms, indexed by EPDS 9 or more at 6-10 weeks postpartum [83].

Pregnancy complications are also associated with postpartum depression and anxiety, although it is difficult to disentangle the underlying disease process from the outcome for the neonate. Hoedjes et al. [84] followed 161 women with mild or severe pre-eclampsia through 26 weeks' postpartum, and measured maternal mood symptoms using the EPDS 
[84]. Women with severe disease had higher scores than women with mild disease at both 6 and 12 weeks after birth, and they were more likely to have a score of 13 or more at 6 weeks $(21.8 v 5.6 \% ; P=0.03)$. Women with severe pre-eclampsia, however, were also far more likely to have an infant admitted to the neonatal intensive care unit $(71.3 \% v 14.3 \%)$ and to have a neonatal loss $(5.1 \% v 0 \%)$. In multivariate models adjusting for neonatal intensive care unit admission and neonatal loss, severe preeclampsia was no longer associated with EPDS score.

These results reflect the high prevalence of depression and anxiety reported among mothers with infants admitted to neonatal intensive care. After a preterm birth, between 22 and $66 \%$ of mothers have clinically significant depression symptoms [85-91], and 24-44\% meet criteria for acute stress disorder $[89,92,93]$.

These mediating factors become important in quantifying the association between perinatal depression and long-term maternal health. Women who have given birth preterm face increased all-cause and cardiovascular mortality, compared with women who have had uncomplicated term births, and this risk is increased for mothers whose pregnancies were complicated by pre-eclampsia [94]. Both pre-eclampsia [95,96] and gestational diabetes $[97,98]$ are associated with lifetime risk of cardiometabolic disease. The extent to which perinatal depression contributes to these adverse long-term health outcomes is not known. A recent meta-analysis, however, found evidence for a bidirectional relationship between depression and metabolic syndrome [99]. The investigators suggest that obesity and inflammation, as well as hypothalamic pituitary adrenal axis and sympathetic nervous system activation, may underlie both depression and metabolic syndrome in non-pregnant women. Similar mechanisms may also link pregnancy complications with perinatal depression.

\section{Perinatal depression and lactation}

Perinatal mood disorders are associated with decreased initiation [77] and reduced duration of breast feeding [100]. The direction of this association is unclear. Although some investigators have suggested that the absence of breast feeding triggers perinatal mood disorders, prospective studies suggest that symptoms of anxiety and depression occur before cessation of breast feeding. In a study of 1123 women, Paul et al. [101] found that early postpartum anxiety, indexed by STAI State 40 or more, was associated with reduced breast feeding duration. In analyses stratified by parity, this effect remained significant among primiparous mothers, but not among multiparous mothers. In the Norwegian Mother and Child Cohort Study (MoBa), Ystrom [102] quantified the association between prenatal mood symptoms, indexed by the Hopkins Symptoms Checklist at 30 weeks' gestation, and mode of infant feeding and symptoms at 6 months' postpartum. Women with prenatal symptoms who were bottle-feeding at 6 months had the most severe mood symptoms [102]. Ystrom suggests that these results show that cessation of breast feeding worsens mood symptoms. It is also plausible, however, that worsening mood symptoms lead to cessation of breast feeding.

Longitudinal data suggest that women with early breast-feeding difficulties are at risk for depressive symptoms. In a prospective cohort study of 2586 US women, those who reported severe pain in the first 2 weeks of feeding were twice as likely to report depression symptoms, indexed by EPDS 13 or more, at 2 months postpartum. Several neuroendocrine mechanisms affect both breast feeding and maternal mood [103], and may underlie the observed association.

Perinatal mood disorders may affect long-term maternal health through effects on breastfeeding initiation and duration. In observational studies, never or shortened breast feeding is 
associated with increased maternal risks of breast cancer [104] ovarian cancer [105] type 2 diabetes [106], hypertension [107], and cardiovascular disease [108] These associations may reflect immunologic [109] and metabolic effects of breast feeding [110], or they may reflect an underlying psychobiological vulnerability that affects both breast feeding outcome and long-term health.

\section{Clinical implications and directions for future research}

Existing data suggest that psychiatric, obstetrical, and medical complications during pregnancy and the puerperium provide a window into a woman's long-term health. Women with a prior history of perinatal mood disorder (unipolar and bipolar depression) are at significantly increased risk for a recurrent episode in both the context of childbearing and outside of the perinatal period. Furthermore, evidence suggests that women with perinatal mental illness may be more likely to develop pregnancy complications, and thus may be at increased risk of long-term metabolic disease. For clinical practice, these associations underscore the importance of carefully screening and treating women with perinatal mental illness to ensure the best possible long-term outcomes. Furthermore, women with complicated pregnancies and breast-feeding difficulties require careful screening for comorbid psychiatric illness.

Such early screening and treatment may both mitigate the primary disease process and reduce the risk of comorbid conditions. For example, a randomised-controlled trial conducted in Australia suggests that glucose control may reduce depressive symptoms. Women with mild gestational diabetes were randomised to usual care or treated with diet, glycaemic monitoring, and insulin, if needed [111]. Women in the treatment group were less likely to develop pre-eclampsia $(12 \% v 18 \% ; P=0.02)$, gained less weight during their pregnancy $(8.1 \vee 9.8 \mathrm{~kg} ; P=0.01)$, and were less likely to have an EPDS over 12 at 3 months postpartum $(8 \% \vee 17 \% ; P=0.001)$. These results suggest a causal association between obesity, glucose intolerance, and perinatal mood disorders. A recent randomisedcontrolled trial of a lifestyle intervention among obese women in Belgium found that both a motivational interviewing intervention and a health lifestyle brochure reduced second trimester anxiety and gestational weight gain [112], suggesting that treatment of maternal mental illness may reduce metabolic complications of pregnancy. These data suggest that integrated interventions that address maternal mental health, diet and physical activity, may positively affect long-term maternal cardiometabolic health.

Several mechanisms may link perinatal mental illness with both pregnancy complications and breast-feeding difficulties. Recent work suggests that perinatal depression and anxiety are associated with reduced levels of the neuropeptide oxytocin [113,114]. In addition to its well-described role in partuition and lactation, oxytocin plays an integral role in stress physiology. Oxytocin receptors are present in lymphocytes, as well as in the heart and vasculature, suggesting that this hormone may influence inflammation and vascular reactivity [115]. Furthermore, in animal models, oxytocin-deficient mice develop late-onset obesity [116], and peripheral oxytocin infusion induces weight loss in low-fat diet and highfat diet fed rats [117]. Thus, disruptions in oxytocin signalling may be one of the mechanisms underlying psychobiological vulnerability to perinatal mood disorders, pregnancy complications and breast-feeding difficulties.

\section{Conclusion}

Childbirth acts as a powerful trigger for mood episodes in some women, and women with histories of a mood disorder are particularly vulnerable. Risk of recurrence of perinatal mental illness is considerable, both in the context of childbearing and outside of the perinatal 
period. Thus, perinatal mental illness does have long-term psychiatric outcomes that must be appropriately managed and addressed by the woman in partnership with her providers. Important evidence also links perinatal mental illness with obstetrical complications and reduced lactation initiation and duration. Perinatal depression, anxiety, or both, may be an independent risk factor for retained gestational weight gain and, consequently, long-term risk that may contribute directly to subsequent cardiometabolic disease through both neuroendocrine mechanisms and the effects of mental illness on health behaviours.

Future studies of mechanisms underlying perinatal depression and pregnancy complications may identify new neuroendocrine systems that contribute to morbidity in the puerperium. Investigators should also test the extent to which interventions to prevent or treat perinatal mood symptoms may reduce pregnancy complications and improve long-term maternal health. Ultimately, improved understanding of the underlying pathophysiology of perinatal mental illness will lead to improved prospective identification of at risk women, and implementation of targeted and effective treatments that will confer enhanced health outcomes for the women, her child and family.

\section{References}

1. Misra DP, Guyer B, Allston A. Integrated perinatal health framework. A multiple determinants model with a life span approach. Am J Prev Med. 2003; 25:65-75. [PubMed: 12818312]

2. Saade GR. Pregnancy as a window to future health [editorial comment]. Obstet Gynecol. 2009; 114:958-60. [PubMed: 20168094]

3. O'Hara MW, Swain AM. Rates and risk of postpartum depression: a meta-analysis. Int Rev Psychiatry. 1996; 8:37-54.

4. Flynn HA, Davis M, Marcus SM, et al. Rates of maternal depression in pediatric emergency department and relationship to child service utilization. Gen Hosp Psychiatry. 2004; 26:316-22. [PubMed: 15234828]

5. Marcus S, Lopez JF, McDonough S, et al. Depressive symptoms during pregnancy: impact on neuroendocrine and neonatal outcomes. Infant Behav Dev. 2011; 34:26-34. [PubMed: 21035873]

6 . Halbreich $U$. The association between pregnancy processes, preterm delivery, low birth weight, and postpartum depressions: the need for interdisciplinary integration [review]. Am J Obstet Gynecol. 2005; 193:1312-22. [PubMed: 16202720]

7. Ibanez G, Charles MA, Forhan A, et al. Depression and anxiety in women during pregnancy and neonatal outcome: data from the EDEN mother-child cohort. Early Hum Dev. 2012; 88:643-9. [PubMed: 22361259]

8. Grote NK, Bridge JA, Gavin AR, et al. A meta-analysis of depression during pregnancy and the risk of preterm birth, low birth weight, and intrauterine growth restriction. Arch Gen Psychiatry. 2010; 67:1012-24. [PubMed: 20921117]

9. Gentile S. Suicidal mothers. J Inj Violence Res. 2011; 3:90-7. [PubMed: 21498972]

10. Petik D, Czeizel B, Banhidy F, et al. A study of the risk of mental retardation among children of pregnant women who have attempted suicide by means of a drug overdose. J Inj Violence Res. 2012; 4:10-9. [PubMed: 21502792]

11. Gidai J, Acs N, Banhidy F, et al. Congenital abnormalities in children of 43 pregnant women who attempted suicide with large doses of nitrazepam. Pharmacoepidemiol Drug Saf. 2010; 19:175-82. [PubMed: 19998314]

12. McMahon C, Barnett B, Kowalenko N, et al. Psychological factors associated with persistent postnatal depression: past and current relationships, defence styles and the mediating role of insecure attachment style. J Affect Disord. 2005; 84:15-24. [PubMed: 15620381]

13. Dipietro JA, Costigan KA, Sipsma HL. Continuity in self-report measures of maternal anxiety, stress, and depressive symptoms from pregnancy through two years postpartum. J Psychosom Obstet Gynaecol. 2008; 29:115-24. [PubMed: 18655259]

14. Gaynes BN, Gavin N, Meltzer-Brody S, et al. Perinatal depression: prevalence, screening accuracy, and screening outcomes. Evid Rep Technol Assess (Summ). Feb.2005 :119. 
15. Meltzer-Brody S, Bledsoe-Mansori SE, Johnson N, et al. A prospective study of perinatal depression and trauma history in pregnant minority adolescents. Am J Obstet Gynecol. 2013; 208(211):e1-7. [PubMed: 23246315]

16. Milgrom J, Gemmill AW, Bilszta JL, et al. Antenatal risk factors for postnatal depression: a large prospective study. J Affect Disord. 2008; 108:147-57. [PubMed: 18067974]

17. Lindahl V, Pearson JL, Colpe L. Prevalence of suicidality during pregnancy and the postpartum. Arch Womens Ment Health. 2005; 8:77-87. [PubMed: 15883651]

18. Austin MP, Kildea S, Sullivan E. Maternal mortality and psychiatric morbidity in the perinatal period: challenges and opportunities for prevention in the Australian setting. Med J Aust. 2007; 186:36-47.

19. McLearn KT, Minkovitz CS, Strobino DM, et al. Maternal depressive symptoms at 2 to 4 months post partum and early parenting practices. Arch Pediatr Adolesc Med. 2006; 160:279-84. [PubMed: 16520447]

20. Paulson JF, Dauber S, Leiferman JA. Individual and combined effects of postpartum depression in mothers and fathers on parenting behavior. Pediatrics. 2006; 118:659-68. [PubMed: 16882821]

21. Paulson JF, Bazemore SD. Prenatal and postpartum depression in fathers and its association with maternal depression: a meta-analysis. JAMA. 2010; 303:1961-9. [PubMed: 20483973]

22. Beck CT. A meta-analysis of predictors of postpartum depression. Nurs Res. 1996; 45:297-303. [PubMed: 8831657]

23. Di Florio A, Forty L, Gordon-Smith K, et al. Perinatal episodes across the mood disorder spectrum. JAMA Psychiatry. 2013; 70:168-75. [PubMed: 23247604]

24. Forty L, Jones L, Macgregor S, et al. Familiality of postpartum depression in unipolar disorder: results of a family study. Am J Psychiatry. 2006; 163:1549-53. [PubMed: 16946179]

25. Viguera AC, Tondo L, Koukopoulos AE, et al. Episodes of mood disorders in 2252 pregnancies and postpartum periods. Am J Psychiatry. 2011; 168:1179-85. [PubMed: 21799064]

26. Cohen LS, Wang B, Nonacs R, et al. Treatment of mood disorders during pregnancy and postpartum. Psychiatr Clin North Am. 2010; 33:273-93. [PubMed: 20385337]

27. Viguera AC, Nonacs R, Cohen LS, et al. Risk of recurrence of bipolar disorder in pregnant and nonpregnant women after discontinuing lithium maintenance. Am J Psychiatry. 2000; 157:179-84. [PubMed: 10671384]

28. Viguera AC, Whitfield T, Baldessarini RJ, et al. Risk of recurrence in women with bipolar disorder during pregnancy: prospective study of mood stabilizer discontinuation. Am J Psychiatry. 2007; 164:1817-24. [PubMed: 18056236]

29. Wisner KL, Sit DK, McShea MC, et al. Onset timing, thoughts of self-harm, and diagnoses in postpartum women with screen-positive depression findings. JAMA Psychiatry. 2013; 70:490-8. [PubMed: 23487258]

30. Austin MP, Hadzi-Pavlovic D, Priest SR, et al. Depressive and anxiety disorders in the postpartum period: how prevalent are they and can we improve their detection? Arch Womens Ment Health. 2010; 13:395-401. [PubMed: 20232218]

31. Munk-Olsen T, Laursen TM, Pedersen CB, et al. New parents and mental disorders: a populationbased register study. JAMA. 2006; 296:2582-9. [PubMed: 17148723]

32. Wisner KL, Perel JM, Peindl KS, et al. Prevention of recurrent postpartum depression: a randomized clinical trial. J Clin Psychiatry. 2001; 62:82-6. [PubMed: 11247106]

33. Rubertsson C, Wickberg B, Gustavsson P, et al. Depressive symptoms in early pregnancy, two months and one year postpartum-prevalence and psychosocial risk factors in a national Swedish sample. Arch Womens Ment Health. 2005; 8:97-104. [PubMed: 15883652]

34. Wisner KL, Moses-Kolko EL, Sit DK. Postpartum depression: a disorder in search of a definition. Arch Womens Ment Health. 2010; 13:37-40. [PubMed: 20127453]

35. Bloch M, Daly RC, Rubinow DR. Endocrine factors in the etiology of postpartum depression. Compr Psychiatry. 2003; 44:234-46. [PubMed: 12764712]

36. Bloch M, Rubinow DR, Schmidt PJ, et al. Cortisol response to ovine corticotropin-releasing hormone in a model of pregnancy and parturition in euthymic women with and without a history of postpartum depression. J Clin Endocrinol Metab. 2005; 90:695-9. [PubMed: 15546899] 
37. Murphy-Eberenz K, Zandi PP, March D, et al. Is perinatal depression familial? J Affect Disord. 2006; 90:49-55. [PubMed: 16337009]

38. Treloar SA, Martin NG, Bucholz KK, et al. Genetic influences on post-natal depressive symptoms: findings from an Australian twin sample. Psychol Med. 1999; 29:645-54. [PubMed: 10405086]

39. Mahon PB, Payne JL, MacKinnon DF, et al. Genome-wide linkage and follow-up association study of postpartum mood symptoms. Am J Psychiatry. 2009; 166:1229-37. [PubMed: 19755578]

40. Tarantino LM, Sullivan PF, Meltzer-Brody S. Using animal models to disentangle the role of genetic, epigenetic and environmental influences on behavioral outcomes associated with maternal anxiety and depression [review]. Front Psychiatry. 2011; 18:2.

41. Meltzer-Brody S. New insights into perinatal depression: pathogenesis and treatment during pregnancy and postpartum [review]. Dialogues Clin Neurosci. 2011; 13:89-100. [PubMed: 21485749]

42. Wisner KL, Perel JM, Peindl KS, et al. Prevention of postpartum depression: a pilot randomized clinical trial. Am J Psychiatry. 2004; 161:1290-2. [PubMed: 15229064]

43. Dennis CL. Psychosocial and psychological interventions for prevention of postnatal depression: systematic review. BMJ. 2005; 331:15. [PubMed: 15994688]

44. Clatworthy J. The effectiveness of antenatal interventions to prevent postnatal depression in highrisk women. J Affect Disord. 2012; 137:25-34. [PubMed: 21514960]

45. Wisner KL, Parry BL, Piontek CM. Clinical practice. Postpartum depression. N Engl J Med. 2002; 347:194-9. [PubMed: 12124409]

46. Jones I, Craddock N. Searching for the puerperal trigger: molecular genetic studies of bipolar affective puerperal psychosis. Psychopharmacol Bull. 2007; 40:115-28. [PubMed: 17514190]

47. Jones I, Craddock N. Familiality of the puerperal trigger in bipolar disorder: results of a family study. Am J Psychiatry. 2001; 158:913-7. [PubMed: 11384899]

48. Jones I, Hamshere M, Nangle JM, et al. Bipolar affective puerperal psychosis: genome-wide significant evidence for linkage to chromosome 16. Am J Psychiatry. 2007; 164:1099-104. [PubMed: 17606662]

49. Munk-Olsen T, Laursen TM, Meltzer-Brody S, et al. Psychiatric disorders with postpartum onset: possible early manifestations of bipolar affective disorders. Arch Gen Psychiatry. 2012; 69:42834. [PubMed: 22147807]

50. Munk-Olsen T, Laursen TM, Mendelson T, et al. Risks and predictors of readmission for a mental disorder during the postpartum period. Arch Gen Psychiatry. 2009; 66:189-95. [PubMed: 19188541]

51. Cohen LS, Sichel DA, Robertson LM, et al. Postpartum prophylaxis for women with bipolar disorder. Am J Psychiatry. 1995; 152:1641-5. [PubMed: 7485628]

52. Chaudron LH, Pies RW. The relationship between postpartum psychosis and bipolar disorder: a review. J Clin Psychiatry. 2003; 64:1284-92. [PubMed: 14658941]

53. Bergink V, Bouvy PF, Vervoort JS, et al. Prevention of postpartum psychosis and mania in women at high risk. Am J Psychiatry. 2012; 169:609-15. [PubMed: 22407083]

54. Yonkers KA, Wisner KL, Stowe Z, et al. Management of bipolar disorder during pregnancy and the postpartum period. Am J Psychiatry. 2004; 161:608-20. [PubMed: 15056503]

55. Payne JL, Roy PS, Murphy-Eberenz K, et al. Reproductive cycle-associated mood symptoms in women with major depression and bipolar disorder. J Affect Disord. 2007; 99:221-9. [PubMed: 17011632]

56. Spinelli MG. Postpartum psychosis: detection of risk and management. Am J Psychiatry. 2009; 166:405-8. [PubMed: 19339365]

57. Labad J, Menchon JM, Alonso P, et al. Female reproductive cycle and obsessive-compulsive disorder. J Clin Psychiatry. 2005; 66:428-35. [PubMed: 15816784]

58. Altemus M, Neeb CC, Davis A, et al. Phenotypic differences between pregnancy-onset and postpartum-onset major depressive disorder. J Clin Psychiatry. 2012; 73:e1485-91. [PubMed: 23290332]

59. Uguz F, Akman C, Kaya N, et al. Postpartum-onset obsessive-compulsive disorder: incidence, clinical features, and related factors. J Clin Psychiatry. 2007; 68:132-8. [PubMed: 17284141] 
60. Brandes M, Soares CN, Cohen LS. Postpartum onset obsessive-compulsive disorder: diagnosis and management. Arch Womens Ment Health. 2004; 7:99-110. [PubMed: 15083345]

61. Abramowitz JS, Meltzer-Brody S, Leserman J, et al. Obsessional thoughts and compulsive behaviors in a sample of women with postpartum mood symptoms. Arch Women Ment Health. 2010; 13:523-30.

62. Vulink NC, Denys D, Bus L, et al. Female hormones affect symptom severity in obsessivecompulsive disorder. Int Clin Psychopharmacol. 2006; 21:171-5. [PubMed: 16528139]

63. Leckman JF, Goodman WK, North WG, et al. The role of central oxytocin in obsessive compulsive disorder and related normal behavior. Psychoneuroendocrinology. 1994; 19:723-49. [PubMed: 7991761]

64. Leckman JF, Goodman WK, North WG, et al. Elevated cerebrospinal fluid levels of oxytocin in obsessive-compulsive disorder. Comparison with Tourette's syndrome and healthy controls. Arch Gen Psychiatry. 1994; 51:782-92. [PubMed: 7524462]

65. Abramowitz JS, Nelson CA, Rygwall R, et al. The cognitive mediation of obsessive-compulsive symptoms: a longitudinal study. J Anxiety Disord. 2007; 21:91-104. [PubMed: 16806800]

66. Challacombe FL, Salkovskis PM. Intensive cognitive-behavioural treatment for women with postnatal obsessive-compulsive disorder: a consecutive case series. Behav Res Ther. 2011; 49:422-6. [PubMed: 21489404]

67. Misri S, Milis L. Obsessive-compulsive disorder in the postpartum: open-label trial of quetiapine augmentation. J Clin Psychopharmacol. 2004; 24:624-7. [PubMed: 15538124]

68. Phelan S. Pregnancy: a "teachable moment" for weight control and obesity prevention. Am J Obstet Gynecol. 2009

69. Herring SJ, Rich-Edwards JW, Oken E, et al. Association of postpartum depression with weight retention 1 year after childbirth. Obesity. 2008; 16:1296-301. [PubMed: 18369338]

70. Taveras EM, Rifas-Shiman SL, Rich-Edwards JW, et al. Association of maternal short sleep duration with adiposity and cardiometabolic status at 3 years postpartum. Obesity. 2011; 19:1718. [PubMed: 20489690]

71. Bodnar LM, Wisner KL, Moses-Kolko E, et al. Prepregnancy body mass index, gestational weight gain, and the likelihood of major depressive disorder during pregnancy. J Clin Psychiatry. 2009; 70:1290-6. [PubMed: 19607761]

72. Bogaerts AF, Van den Bergh BR, Witters I, et al. Anxiety during early pregnancy predicts postpartum weight retention in obese mothers. Obesity (Silver Spring). 2013 epub ahead of print.

73. Pedersen P, Baker JL, Henriksen TB, et al. Influence of psychosocial factors on postpartum weight retention. Obesity. 2011; 19:639-46. [PubMed: 20706201]

74. Rooney B, Schauberger C. Excess pregnancy weight gain and long-term obesity: one decade later. Obstet Gynecol. 2002; 100:245-52. [PubMed: 12151145]

75. Rooney BL, Schauberger CW, Mathiason MA. Impact of perinatal weight change on long-term obesity and obesity-related illnesses. Obstet Gynecol. 2005; 106:1349-56. [PubMed: 16319262]

76. Prairie BA, Wisniewski SR, Luther JF, et al. Postpartum lipid levels in women with major depression. J Womens Health. 2012; 21:534-8.

77. Grigoriadis S, Vonderporten EH, Mamisashvili L, et al. The impact of maternal depression during pregnancy on perinatal outcomes: a systematic review and meta-analysis. J Clin Psychiatry. 2013; 74:e321-41. [PubMed: 23656857]

78. Kurki T, Hiilesmaa V, Raitasalo R, et al. Depression and anxiety in early pregnancy and risk for preeclampsia. Obstet Gynecol. 2000; 95:487-90. [PubMed: 10725477]

79. Qiu C, Williams MA, Calderon-Margalit R, et al. Preeclampsia risk in relation to maternal mood and anxiety disorders diagnosed before or during early pregnancy. Am J Hypertens. 2009; 22:397402. [PubMed: 19197246]

80. Henrichs J, Schenk JJ, Roza SJ, et al. Maternal psychological distress and fetal growth trajectories: the Generation R Study. Psychol Med. 2010; 40:633-43. [PubMed: 19656431]

81. Vollebregt KC, van der Wal MF, Wolf $\mathrm{H}$, et al. Is psychosocial stress in first ongoing pregnancies associated with pre-eclampsia and gestational hypertension? BJOG. 2008; 115:607-15. [PubMed: 18333942] 
82. Kozhimannil KB, Pereira MA, Harlow BL. Association between diabetes and perinatal depression among low-income mothers. JAMA. 2009; 301:842-7. [PubMed: 19244191]

83. Nicklas JM, Miller LJ, Zera CA, et al. Factors associated with depressive symptoms in the early postpartum period among women with recent gestational diabetes mellitus. Matern Child Health J. 2012 epub ahead of print.

84. Hoedjes M, Berks D, Vogel I, et al. Postpartum depression after mild and severe preeclampsia. J Womens Health (Larchmt). 2011; 20:1535-42. [PubMed: 21815820]

85. Miles MS, Holditch-Davis D, et al. Depressive symptoms in mothers of prematurely born infants. J Dev Behav Pediatr. 2007; 28:36-44. [PubMed: 17353730]

86. Meyer EC, Coll CT, Lester BM, et al. Family-based intervention improves maternal psychological well-being and feeding interaction of preterm infants. Pediatrics. 1994; 93:241-6. [PubMed: 8121735]

87. Miles MS, Holditch-Davis D, Burchinal P, et al. Distress and growth outcomes in mothers of medically fragile infants. Nurs Res. 1999; 48:129-40. [PubMed: 10337844]

88. Davis L, Edwards H, Mohay H, et al. The impact of very premature birth on the psychological health of mothers. Early Hum Dev. 2003; 73:61-70. [PubMed: 12932894]

89. Silverstein M, Feinberg E, Young R, et al. Maternal depression, perceptions of children's social aptitude and reported activity restriction among former very low birthweight infants. Arch Dis Child. 2010; 95:521-5. [PubMed: 20522473]

90. Carter JD, Mulder RT, Bartram AF. Infants in a neonatal intensive care unit: parental response. Arch Dis Child Fetal Neonatal Ed. 2005; 90:F109-13. [PubMed: 15724032]

91. Poehlmann J, Schwichtenberg AJ, Bolt D, et al. Predictors of depressive symptom trajectories in mothers of preterm or low birth weight infants. J Fam Psychol. 2009; 23:690-704. [PubMed: 19803605]

92. Shaw RJ, Deblois T, Ikuta L, et al. Acute stress disorder among parents of infants in the neonatal intensive care nursery. Psychosomatics. 2006; 47:206-12. [PubMed: 16684937]

93. Vanderbilt D, Bushley T, Young R, et al. Acute posttraumatic stress symptoms among urban mothers with newborns in the neonatal intensive care unit: a preliminary study. J Dev Behav Pediatr. 2009; 30:50-6. [PubMed: 19194322]

94. Irgens HU, Reisaeter L, Irgens LM, et al. Long term mortality of mothers and fathers after preeclampsia: population based cohort study. BMJ. 2001; 323:1213-7. [PubMed: 11719411]

95. Wolf M, Hubel C, Lam C, et al. Preeclampsia and future cardiovascular disease: potential role of altered angiogenesis and insulin resistance. J Clin Endocrinol Metab. 2004; 89:6239-43. [PubMed: 15579783]

96. Wolf M, Sandler L, Jimenez-Kimble R, et al. Insulin resistance but not inflammation is associated with gestational hypertension. Hypertension. 2002; 40:886-91. [PubMed: 12468574]

97. Retnakaran R, Qi Y, Connelly PW, et al. Glucose intolerance in pregnancy and postpartum risk of metabolic syndrome in young women. J Clin Endocrinol Metab. 2010; 95:670-7. [PubMed: 19926711]

98. Retnakaran R, Shah BR. Mild glucose intolerance in pregnancy and risk of cardiovascular disease: a population-based cohort study. CMAJ. 2009; 181:371-6. [PubMed: 19703913]

99. Pan A, Keum N, Okereke OI, et al. Bidirectional association between depression and metabolic syndrome: a systematic review and meta-analysis of epidemiological studies. Diabetes Care. 2012; 35:1171-80. [PubMed: 22517938]

100. Dennis C-L, McQueen K. The relationship between infant-feeding outcomes and postpartum depression: a qualitative systematic review. Pediatrics. 2009; 123:e736-51. [PubMed: 19336362]

101. Paul IM, Downs DS, Schaefer EW, et al. Postpartum anxiety and maternal-infant health outcomes. Pediatrics. 2013; 131:e1218-24. [PubMed: 23460682]

102. Ystrom E. Breastfeeding cessation and symptoms of anxiety and depression: a longitudinal cohort study. BMC Pregnancy Childbirth. 2012; 12:36. [PubMed: 22621668]

103. Stuebe AM, Grewen K, Pedersen CA, et al. Failed lactation and perinatal depression: common problems with shared neuroendocrine mechanisms? J Womens Health. 2012; 21:264-72. 
104. Stuebe AM, Willett WC, Xue F, et al. Lactation and incidence of premenopausal breast cancer: a longitudinal study. Arch Intern Med. 2009; 169:1364-671. [PubMed: 19667298]

105. Danforth KN, Tworoger SS, Hecht JL, et al. Breastfeeding and risk of ovarian cancer in two prospective cohorts. Cancer Causes Control. 2007; 18:517-23. [PubMed: 17450440]

106. Stuebe AM, Rich-Edwards JW, Willett WC, et al. Duration of lactation and incidence of Type 2 Diabetes. JAMA. 2005; 294:2601-10. [PubMed: 16304074]

107. Stuebe AM, Schwarz EB, Grewen K, et al. Duration of lactation and incidence of maternal hypertension: a longitudinal cohort study. Am J Epidemiol. 2011; 174:1147-58. [PubMed: 21997568]

108. Schwarz EB, Stuebe AM, Allison MA, et al. Impact of lactation on risk factors for cardiovascular disease. J Gen Intern Med. 2008; 23:321-2.

109. Cramer DW, Titus-Ernstoff L, McKolanis JR, et al. Conditions associated with antibodies against the tumor-associated antigen MUC1 and their relationship to risk for ovarian cancer. Cancer Epidemiol Biomarkers Prev. 2005; 14:1125-31. [PubMed: 15894662]

110. Stuebe AM, Rich-Edwards JW. The reset hypothesis: lactation and maternal metabolism. Am J Perinatol. 2009; 26:81-8. [PubMed: 19031350]

111. Crowther CA, Hiller JE, Moss JR, et al. Effect of treatment of gestational diabetes mellitus on pregnancy outcomes. N Engl J Med. 2005; 352:2477-86. [PubMed: 15951574]

112. Bogaerts AF, Devlieger R, Nuyts E, et al. Effects of lifestyle intervention in obese pregnant women on gestational weight gain and mental health: a randomized controlled trial. Int J Obes. 2013; 37:814-21.

113. Skrundz M, Bolten M, Nast I, et al. Plasma oxytocin concentration during pregnancy is associated with development of postpartum depression. Neuropsychopharmacology. 2011; 36:1886-93. [PubMed: 21562482]

114. Stuebe AM, Grewen K, Meltzer-Brody S. Association between maternal mood and oxytocin response to breastfeeding. J Womens Health. 2013; 22:352-61.

115. Gimpl G, Fahrenholz F. The oxytocin receptor system: structure, function, and regulation. Physiol Rev. 2001; 81:629-83. [PubMed: 11274341]

116. Camerino C. Low sympathetic tone and obese phenotype in oxytocin-deficient mice. Obesity. 2009; 17:980-4. [PubMed: 19247273]

117. Morton GJ, Thatcher BS, Reidelberger RD, et al. Peripheral oxytocin suppresses food intake and causes weight loss in diet-induced obese rats. Am J Physiol. 2012; 302:E134-44. 


\section{Practice points}

- Perinatal mental illness has potential serious long-term psychiatric and medical consequences for the mother, her baby, and the family.

- Childbirth acts as a powerful trigger for depressive episodes in some women and likely has underlying biological causes.

- Women with histories of mood disorders are particularly vulnerable to a psychobiological postpartum trigger.

- Most women with perinatal mental illness will experience unipolar major depressive disorder.

- Recurrence risk of postpartum depression in women who have suffered one episode of major depression after childbirth is about $25 \%$, and can often become a chronic issue.

- Women with bipolar disorder are at increased risk of depression, mania, and psychosis in the perinatal period.

- Discontinuation of medication during pregnancy significantly increases the risk of post-partum recurrence of perinatal mental illness in women with bipolar disorder.

- Perinatal mental illness needs to be taken seriously in women with more severe mood disorders, and long-term follow-up is critical in women with bipolar disorder. 


\section{Research agenda}

- Future studies of mechanisms underlying perinatal depression and pregnancy complications may identify new neuroendocrine systems and biomarkers that contribute to morbidity in the puerperium.

- Longitudinal studies of mood disorders across the reproductive lifecycle are needed to clearly identify long-term outcomes of perinatal mental illness in women and their offspring.

- Investigators should also test the extent to which interventions to prevent or treat perinatal mood symptoms may reduce pregnancy complications and improve long-term maternal health.

- Ultimately, improved understanding of the underlying pathophysiology of perinatal mental illness will lead to improved prospective identification of women at risk.

- Implementation of carefully studied targeted and effective treatments will confer enhanced health outcomes for the women, her child, and family. 


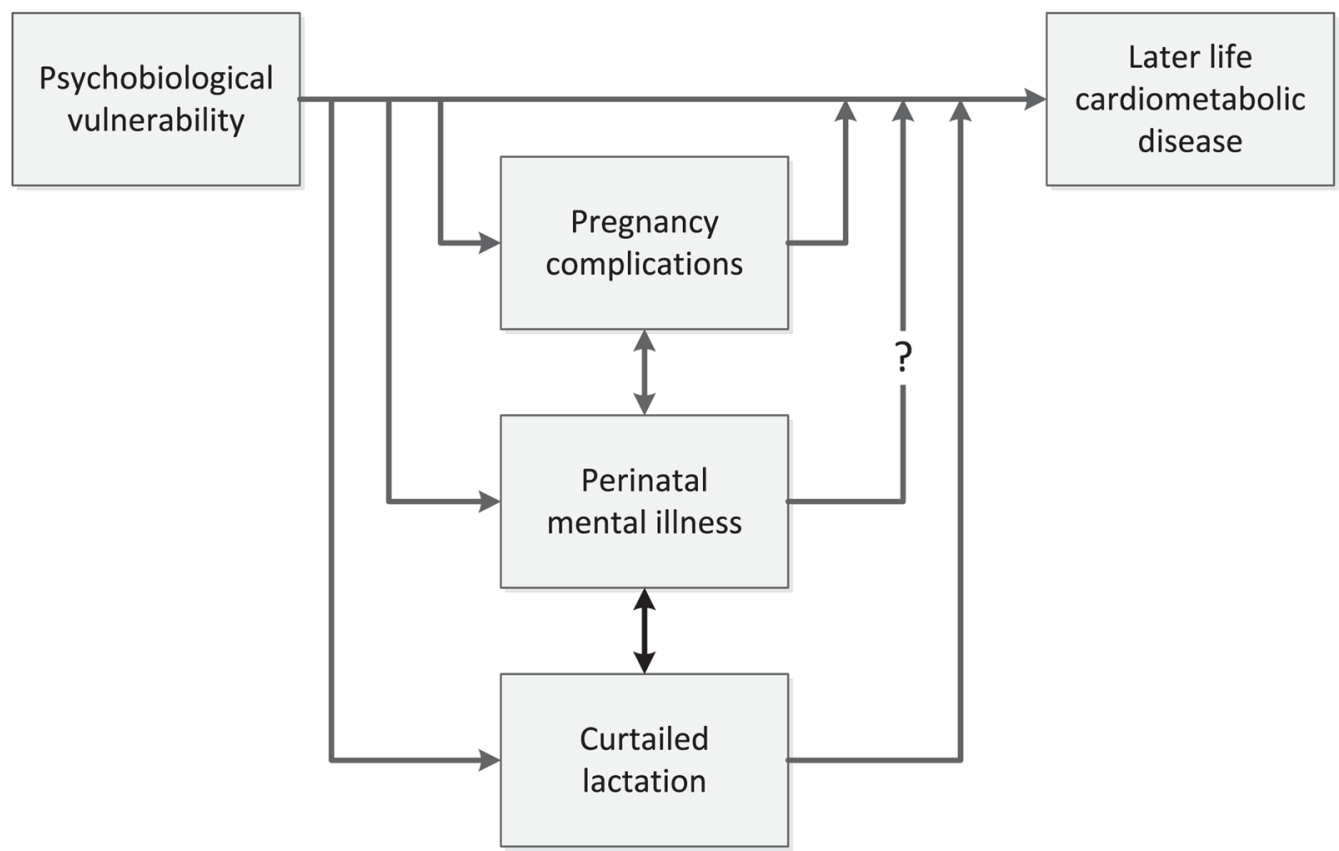

Fig. 1. 